\title{
Nut consumption and risk of pancreatic cancer in women
}

\author{
Y Bao*,1 , F B Hu ${ }^{1,2,3}$, E L Giovannucci ${ }^{1,2,3}$, B M Wolpin ${ }^{4,5}$, M J Stampfer ${ }^{1,2,3}$, W C Willett ${ }^{1,2,3}$ and C S Fuchs a $^{1,5}$ \\ ${ }^{1}$ Channing Division of Network Medicine, Department of Medicine, Brigham and Women's Hospital and Harvard Medical School, \\ 181 Longwood Avenue, Boston, MA 02115, USA; 'Department of Epidemiology, Harvard School of Public Health, Boston, MA, \\ USA; ${ }^{3}$ Department of Nutrition, Harvard School of Public Health, Boston, MA, USA; ${ }^{4}$ Department of Medicine, Brigham and \\ Women's Hospital and Harvard Medical School, Boston, MA, USA and ${ }^{5}$ Department of Medical Oncology, Dana-Farber Cancer \\ Institute, Boston, MA, USA
}

Background: Increasing nut intake has been associated with reduced risk of diabetes mellitus, which is a risk factor for pancreatic cancer.

Methods: We prospectively followed 75680 women in the Nurses' Health Study, and examined the association between nut consumption and pancreatic cancer risk. Participants with a previous history of cancer were excluded. Nut consumption was assessed at baseline and updated every 2 to 4 years. Relative risks (RRs) and 95\% confidence intervals (95\% Cls) were estimated using Cox proportional hazards models.

Results: We documented 466 incident cases of pancreatic cancer. After adjusting for age, height, smoking, physical activity, and total energy intake, women who consumed a $28-\mathrm{g}(1 \mathrm{oz})$ serving size of nuts $\geqslant 2$ times per week experienced a significantly lower risk of pancreatic cancer $(\mathrm{RR}, 0.65 ; 95 \% \mathrm{Cl}, 0.47-0.92 ; P$ for trend $=0.007)$ when compared with those who largely abstained from nuts. The results did not appreciably change after further adjustment for body mass index (BMI) and history of diabetes mellitus $(\mathrm{RR}, 0.68 ; 95 \% \mathrm{Cl}, 0.48-0.95 ; P$ for trend=0.01). The inverse association persisted within strata defined by BMl, physical activity, smoking, and intakes of red meat, fruits, and vegetables.

Conclusion: Frequent nut consumption is inversely associated with risk of pancreatic cancer in this large prospective cohort of women, independent of other potential risk factors for pancreatic cancer.

Pancreatic cancer is among the most fatal malignancies, representing the fourth most common cause for cancer-related mortality in the United States (Jemal et al, 2010). Primary prevention remains the most feasible approach to reducing the incidence of pancreatic cancer, which makes the identification of modifiable risk factors essential. Unfortunately, very few modifiable risk factors have been identified. The 2009 World Cancer Research Fund/American Institute for Cancer Research (WCRF/AICR) report concluded that, beyond cigarette smoking, body fatness was the only convincing modifiable risk factor for pancreatic cancer (WCRF/ AICR, 2009).

Extensive evidence suggests that common states of insulin resistance such as obesity (Larsson et al, 2007) are associated with an increased risk of pancreatic cancer - possibly mediated through chronic hyperglycaemia and hyperinsulinaemia. Type II diabetes mellitus, a potential consequence of pancreatic cancer, is also a risk factor for this fatal disease (Everhart and Wright, 1995; Elena et al, 2013). Recent studies demonstrate that elevated baseline plasma insulin and C-peptide significantly increased subsequent pancreatic cancer risk (Stolzenberg-Solomon et al, 2005; Michaud et al, 2007). Nuts are a rich source of bioactive components such as unsaturated fatty acids, fibre, and magnesium (Brufau et al, 2006), which may improve insulin sensitivity (Anderson et al, 1987; Paolisso et al, 1989; Riserus et al, 2009). Data from the National Health and Nutrition Examination Survey (NHANES) found that nut consumption was associated with decreased insulin levels 
(O’Neil et al, 2012) and a lower prevalence of abdominal obesity and metabolic syndrome (O'Neil et al, 2011). Prospective epidemiologic data have further shown that regular nut consumption is associated with lower risk of type II diabetes (Jiang et al, 2002; Villegas et al, 2008). Because diabetes is a consistent risk factor for pancreatic cancer, and insulin resistance is an important underlying mechanism (Giovannucci and Michaud, 2007), we investigated prospectively the association between nut consumption and risk of pancreatic cancer in a large cohort of women in the Nurses' Health Study (NHS).

\section{MATERIALS AND METHODS}

Study population. The NHS began in 1976 when 121700 US female nurses aged 30-55 years returned the initial questionnaire. In 1980, the questionnaire was expanded to include a validated semiquantitative food frequency questionnaire (Willett et al, 1985). Follow-up questionnaires were sent to participants every 2 years to update information on new disease diagnoses and potential risk factors for chronic diseases. The overall follow-up rate exceeded $90 \%$.

For the present analysis, follow-up started in 1980 when dietary information was first assessed. At baseline, 92468 women completed the dietary questionnaire. We excluded 3670 women who had a history of cancer, 1141 women who did not provide information on nut intake, and 11977 women who did not provide information on anthropometric measures or physical activity, or reported implausible nutritional information ( $>9$ missing food items or estimated daily energy intake $<500 \mathrm{kcal}$ or $>3500 \mathrm{kcal}$ ). After these exclusions, 75680 women were eligible for the analyses. This study was approved by the Human Research Committee at the Brigham and Women's Hospital.

Dietary assessment. Dietary intake was obtained from the NHS participants via validated semiquantitative food frequency questionnaires in 1980, 1984, 1986, and every 4 years thereafter. Participants were asked to report their average frequency of intake over the preceding year for a specified serving size of each food. Individual nutrient intakes (e.g., vitamin D intake) were calculated by multiplying the frequency of each food consumed by the nutrient content of the specified portion size and then summing the contributions from all foods.

In the 1980 and 1984 dietary questionnaires, we asked the participants how often, on average, they had consumed nuts (peanut butter not included; serving size, $28 \mathrm{~g}(1 \mathrm{oz})$ ) over the preceding year: never/almost never, 1 to 3 times a month, once a week, 2 to 4 times a week, 5 to 6 times a week, once a day, 2 to 3 times a day, 4 to 6 times a day, or more than 6 times a day. In the 1986, 1990, 1994, 1998, 2002, and 2006 dietary questionnaires, the question for nuts was split into two items: peanuts and other nuts. Total nut consumption was the sum of peanuts and other nuts intake. A validation study of the food frequency questionnaires in the NHS indicated that nut intake was reported with reasonable accuracy; the correlation coefficient was 0.75 between nut intakes assessed by the 1980 questionnaire and by dietary records collected over 4 weeks (Salvini et al, 1989).

Identification of pancreatic cancer cases. Participants were asked to report specified medical conditions, including cancers, that were diagnosed in the 2-year period between each follow-up questionnaire. Whenever a participant (or next of kin for decedents) reported a diagnosis of pancreatic cancer, we asked for permission to obtain the participant's medical records. We also searched the National Death Index to identify deaths among nonrespondents. This method has been shown to capture $>98 \%$ of deaths (Rich-Edwards et al, 1994). If the primary cause of death on the death certificate was a previously unreported pancreatic cancer case, we contacted a family member to obtain permission to retrieve medical records. Study physicians who were blinded to participants' risk factor status reviewed medical records and assigned cancer diagnoses and causes of death. In the NHS cohort, all medical records had complete information on histology (hospitals were recontacted if the original information sent was incomplete). We were able to obtain pathology reports confirming the diagnosis of pancreatic cancer for $91 \%$ of cases. For the other $9 \%$ of cases, we obtained confirmation of the self-reported cancer from a secondary source (e.g., death certificate, physician, or telephone interview of a family member). In our analyses, associations were examined including and excluding cases confirmed by secondary sources; because no differences were observed between these two types of analyses, we included cases confirmed by secondary sources.

Assessment of nondietary factors. At baseline and in all subsequent questionnaires, women were asked about their history of active smoking, including smoking status, time since quitting, and average number of cigarettes smoked daily. Information on physical activity was assessed at baseline and updated every 2 to 4 years. Body mass index (BMI) was calculated from height selfreported at baseline and weight updated every 2 years. Because pancreatic cancer is frequently associated with profound weight loss, we added a 4-year lag period when we updated BMI during follow-up, that is, we used BMI data from the 1976 questionnaire for the follow-up period from 1980 to 1982, 1978 for the interval from 1982 to 1984,1980 for the interval from 1984 to 1986 , and so forth.

Statistical analysis. We computed person-time from the return date of the 1980 questionnaire to the date of pancreatic cancer diagnosis, death from any cause, or the end of follow-up (30 June 2010), whichever came first. We calculated the cumulative average of dietary factors from all dietary questionnaires, using methods for repeated measures described previously ( $\mathrm{Hu}$ et al, 1997). Briefly, we used data from the 1980 questionnaire for the follow-up period from 1980 to 1984, the average of 1980 and 1984 for the interval from 1984 to 1986, and the average of 1980, 1984, and 1986 for the interval from 1986 to 1990, and so forth. For analysis of total nuts, we divided women into four categories according to their frequency of nut consumption: never/almost never (the reference group), 1 to 3 times a month, once a week, and at least 2 times a week. For separate analysis of peanuts and other nuts, we divided women into three categories: never/almost never (the reference group), 1 to 3 times a month, and at least once a week. Relative risks (RRs) and 95\% confidence intervals (CIs) were estimated by Cox proportional hazards models.

In multivariate analyses, we adjusted for potential confounding variables including age, height (quintiles), physical activity (quintiles), smoking (never; past; current 1-14 pack-years; current $15-24$ pack-years; current $\geqslant 25$ pack-years), and total energy intake. We then adjusted for BMI (quintiles) and diabetes (yes/no), to see if the observed association was independent of these potential mediators or confounding factors for the association between nut intake and pancreatic cancer risk. We further adjusted for dietary factors including alcohol (never, 0.1-4.9, 5-14.9, and $\geqslant 15$ g day $^{-1}$ ), multivitamin use (yes/no), and intakes of red meat, fruits, and vegetables, and vitamin D (quintiles). As nut is often considered a component of the Mediterranean dietary pattern and a recent study showed an inverse association between the Mediterranean diet and pancreatic cancer risk (Bosetti et al, 2013), we additionally adjusted for a Mediterranean diet score (Trichopoulou et al, 2003) in a sensitivity analysis to examine whether the association with nuts is independent of the Mediterranean dietary pattern. The $P$-values for trend were calculated by the Wald test of a score variable that contained median values of intake categories. 
To test the robustness of our results, we conducted a sensitivity analysis excluding individuals with diabetes. To rule out any effect of subclinical pancreatic cancer on nut intake, we performed an additional analysis in which we added a 4-year lag period between nut intake assessment and each follow-up period (follow-up started in 1984 for this analysis), that is, we used nut intake from the 1980 questionnaire for the follow-up period from 1984 to 1988, the cumulative average of nut intake in 1980-1984 for the interval from 1988 to 1992, and so forth.

To examine whether the association between nut intake and risk of pancreatic cancer was modified by other factors, we examined the association in subgroups defined by BMI, physical activity, smoking status, and intakes of red meat, fruits, and vegetables. Tests for interaction were performed by the Wald test of crossproduct terms. All statistical analyses were performed with the SAS 9.1 statistical package (SAS Institute, Cary, NC, USA) and all $P$-values are two sided.

\section{RESULTS}

During study follow-up, nut consumption remained relatively constant. Women with more frequent nut consumption were generally leaner, more likely to exercise, and less likely to smoke (Table 1). They also tended to consume more alcohol, multivitamin supplements, and fruits and vegetables.

During 2112234 person-years of follow up from 1980 to 2010 , we documented 466 confirmed incident cases of pancreatic cancer. Frequency of nut consumption was inversely associated with risk of pancreatic cancer (Table 2). Compared with women who largely abstained, participants who consumed a $28 \mathrm{-g}(1 \mathrm{oz})$ serving size of nuts $\geqslant 2$ times per week experienced an age-adjusted $\mathrm{RR}$ of pancreatic cancer of 0.65 (95\% CI, 0.47-0.90; $P$ for trend $=0.005$ ) and a multivariate RR of 0.65 (95\% CI, 0.47-0.92; $P$ for trend $=0.007)$. The RR did not appreciably change after controlling for BMI and history of diabetes (RR, 0.68; 95\% CI, 0.48-0.95; $P$ for trend $=0.01)$. Further controlling for dietary variables, including alcohol, multivitamin use, and intakes of red meat, fruits, and vegetables, and vitamin $\mathrm{D}$, yielded similar results (multivariate RR, 0.68; 95\% CI, $0.48-0.96 ; \quad P$ for trend $=0.01$ ). The results also remained the same when we adjusted for the Mediterranean diet score (multivariate RR, 0.65; 95\% CI, $0.46-0.92$; $P$ for trend $=0.008$ ).

We considered the possibility that occult pancreatic cancer in the years that preceded diagnosis may be have influenced dietary patterns. However, our findings remained essentially unchanged after we added a 4-year lag period between nut intake assessment and each follow-up period (multivariate RR, 0.73; 95\% CI, $0.52-1.03$, comparing $\geqslant 2$ times/week with never/almost never; $P$ for trend $=0.03$ ). Moreover, our results remained consistent after excluding women with a history of diabetes mellitus (multivariate RR, 0.67; 95\% CI, 0.46-0.96, comparing $\geqslant 2$ times/week with never/almost never; $P$ for trend $=0.02$ ).

To examine further the independent association with nut consumption, we repeated the multivariate analyses within subgroups of BMI, physical activity, smoking, and intakes of red meat, fruits, and vegetables (Table 3 ). An inverse association persisted in all subgroups, and we found no apparent modification of the relation between nut consumption and pancreatic cancer risk by these factors.

In analyses of peanuts and other nuts (assessed in 1986) separately, peanuts and other nuts were both inversely associated with risk of pancreatic cancer, although the associations were not statistically significant. The multivariate RRs comparing $\geqslant 2$ times/ week with never/almost never are 0.89 (95\% CI, 0.57-1.39; 27 cases) for peanuts and 0.63 (95\% CI, 0.39-1.03; 20 cases) for other nuts $\left(P_{\text {heterogeneity }}=0.30\right)$.

\begin{tabular}{|c|c|c|c|c|}
\hline & \multicolumn{4}{|c|}{$\begin{array}{l}\text { Frequency of nut consumption } \\
\text { ( } 28 \mathrm{~g} \text { serving) }\end{array}$} \\
\hline & $\begin{array}{l}\text { Never/ } \\
\text { almost } \\
\text { never }\end{array}$ & $\begin{array}{c}1-3 \\
\text { Times } \\
\text { per } \\
\text { month }\end{array}$ & $\begin{array}{l}\text { Once } \\
\text { per } \\
\text { week }\end{array}$ & $\begin{array}{l}\geqslant 2 \text { Times } \\
\text { per week }\end{array}$ \\
\hline $\begin{array}{l}\text { Nut intake, servings } \\
\text { per day }\end{array}$ & 0 & $0.01-0.09$ & $0.10-0.19$ & $\geqslant 0.20$ \\
\hline Person-years & 364282 & 971411 & 388832 & 387709 \\
\hline $\begin{array}{l}\text { Age, years, mean } \\
\text { (s.d.) }\end{array}$ & $55.8(10.9)$ & $59.6(10.9)$ & $60.3(10.8)$ & $60.9(10.8)$ \\
\hline $\begin{array}{l}\text { Height, inches, } \\
\text { mean (s.d.) }\end{array}$ & $64.4(2.4)$ & $64.5(2.4)$ & $64.6(2.4)$ & $64.6(2.4)$ \\
\hline $\begin{array}{l}\text { Body mass index, } \\
\mathrm{kg} \mathrm{m}^{-2} \text {, mean (s.d.) }\end{array}$ & $25.8(5.2)$ & $25.8(5.1)$ & $25.5(4.9)$ & $24.9(4.6)$ \\
\hline $\begin{array}{l}\text { Physical activity, } \\
\text { metabolic } \\
\text { equivalents per } \\
\text { week, mean (s.d.) }\end{array}$ & $13.8(20.4)$ & $15.7(21.0)$ & $17.4(22.1)$ & $19.5(25.1)$ \\
\hline Current smoking, \% & 20.7 & 15.3 & 13.8 & 13.5 \\
\hline $\begin{array}{l}\text { History of diabetes } \\
\text { mellitus, \% }\end{array}$ & 7.8 & 7.1 & 6.6 & 6.0 \\
\hline Multivitamin use, $\%$ & 32.5 & 42.6 & 46.5 & 49.9 \\
\hline $\begin{array}{l}\text { Alcohol intake, } \\
\text { g day }^{-1} \text {, mean (s.d.) }\end{array}$ & $5.2(9.4)$ & $5.6(9.0)$ & $6.6(9.4)$ & $7.4(10.2)$ \\
\hline $\begin{array}{l}\text { Red meat, servings } \\
\text { per day, mean (s.d.) }\end{array}$ & $1.1(0.7)$ & $1.1(0.6)$ & $1.1(0.6)$ & $1.1(0.6)$ \\
\hline $\begin{array}{l}\text { Vegetables, } \\
\text { servings per day, } \\
\text { mean (s.d.) }\end{array}$ & $2.3(1.2)$ & $2.6(1.2)$ & $2.8(1.2)$ & $3.0(1.3)$ \\
\hline $\begin{array}{l}\text { Fruits, servings per } \\
\text { day, mean (s.d.) }\end{array}$ & $2.0(1.2)$ & $2.1(1.1)$ & $2.3(1.2)$ & $2.5(1.3)$ \\
\hline
\end{tabular}

\section{DISCUSSION}

In this large prospective cohort of women, frequent nut consumption was associated with a significantly reduced risk of pancreatic cancer, independent of established or suspected risk factors for pancreatic cancer including age, height, obesity, physical activity, smoking, diabetes, and dietary factors. Women who consumed a $28-\mathrm{g}(1 \mathrm{oz})$ serving size of nuts $\geqslant 2$ times per week had a significantly lower risk of pancreatic cancer, and the inverse association persisted in all subgroup analyses.

To our knowledge, this represents the first study to prospectively assess the association between nut consumption and pancreatic cancer risk. Although a previous case-control study found no association between combined intake of 'nut and tasty snacks' and risk of pancreatic cancer, the analysis was limited by its retrospective design, use of proxy next-of-kin respondents, assessment of diet within 1 year of diagnosis, and lack of data on nut intake exclusive of other snack foods (Bueno de Mesquita et al, 1991).

To date, no specific dietary factor or nutrient has been conclusively associated with the risk of pancreatic cancer (WCRF/AICR, 2009). Nut consumption could influence pancreatic cancer risk through several potential mechanisms, most notably 
Table 2. Relative risks (RRs) and $95 \%$ confidence intervals (Cls) for pancreatic cancer according to nut consumption

Frequency of nut consumption ( $28 \mathrm{~g}$ serving)

\begin{tabular}{|l|c|c|c|c|c|}
\cline { 2 - 5 } & Never/almost never & 1-3 Times per month & Once per week & $\geqslant 2$ Times per week & $\boldsymbol{P}_{\text {trend }}$ \\
\hline Nut intake, servings per day & 0 & $0.01-0.09$ & $0.10-0.19$ & 78 & 77 \\
\hline Cases & 75 & 236 & 388832 & 387709 \\
\hline Person-years & 364282 & 971411 & $0.67(0.49-0.93)$ & $0.65(0.47-0.90)$ & 0.005 \\
\hline Age adjusted & 1.00 & $0.85(0.65-1.10)$ & $0.68(0.49-0.94)$ & $0.65(0.47-0.92)$ & 0.007 \\
\hline Multivariate I $^{\text {a }}$ & 1.00 & $0.86(0.66-1.13)$ & $0.70(0.50-0.97)$ & $0.68(0.48-0.95)$ & 0.01 \\
\hline Multivariate II $^{\mathbf{b}}$ & 1.00 & $0.87(0.67-1.14)$ & $0.71(0.51-0.99)$ & $0.68(0.48-0.96)$ & 0.01 \\
\hline Multivariate III $^{\mathbf{c}}$ & 1.00 & $0.90(0.69-1.18)$ & & \\
\hline
\end{tabular}

${ }^{a}$ Adjusted for age, height (quintiles), physical activity (quintiles), smoking (never; past; current 1-14 pack-years; current 15-24 pack-years; current $\geqslant 25$ pack-years), and total energy intake.

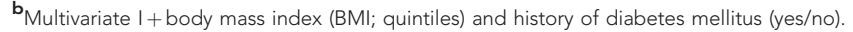

${ }^{c}$ Multivariate II + dietary variables including alcohol (never, $0.1-4.9,5-14.9$, and $\geqslant 15 \mathrm{~g}_{\text {day }}{ }^{-1}$ ), multivitamin use (yes/no), and intakes of red meat, fruits and vegetables, and vitamin $\mathrm{D}$ (quintiles).

Table 3. Multivariate relative risks (RRs) and $95 \%$ confidence intervals (Cls) for pancreatic cancer according to nut consumption, stratified by risk factors ${ }^{\mathrm{a}}$

Frequency of nut consumption ( $28 \mathrm{~g}$ serving)

\begin{tabular}{|c|c|c|c|c|c|c|c|c|}
\hline & \multicolumn{8}{|c|}{ Frequency of nut consumption ( $28 \mathrm{~g}$ serving) } \\
\hline & Cases & $\begin{array}{l}\text { Person- } \\
\text { years }\end{array}$ & $\begin{array}{l}\text { Never/almost } \\
\text { never }\end{array}$ & $\begin{array}{l}\text { 1-3 Times per } \\
\text { month }\end{array}$ & $\begin{array}{l}\text { Once per } \\
\text { week }\end{array}$ & $\begin{array}{l}\geqslant 2 \text { Times per } \\
\text { week }\end{array}$ & $\boldsymbol{P}_{\text {trend }}$ & $\boldsymbol{P}_{\text {interaction }}$ \\
\hline Nut intake, servings per day & & & 0 & $0.01-0.09$ & $0.10-0.19$ & $\geqslant 0.20$ & & \\
\hline Body mass index & & & & & & & & 0.26 \\
\hline$<25 \mathrm{~kg} \mathrm{~m}^{-2}$ & 201 & 1160296 & 1.00 & $0.93(0.61-1.42)$ & $0.75(0.45-1.24)$ & $0.86(0.53-1.41)$ & 0.50 & \\
\hline$\geqslant 25 \mathrm{~kg} \mathrm{~m}^{-2}$ & 265 & 951938 & 1.00 & $0.88(0.62-1.25)$ & $0.68(0.44-1.04)$ & $0.57(0.36-0.91)$ & 0.01 & \\
\hline Physical activity & & & & & & & & 0.97 \\
\hline $\begin{array}{l}\leqslant 9.5 \text { Metabolic equivalents } \\
\text { per week }\end{array}$ & 236 & 1148936 & 1.00 & $1.17(0.76-1.80)$ & $1.03(0.63-1.70)$ & $0.80(0.47-1.34)$ & 0.09 & \\
\hline $\begin{array}{l}>9.5 \text { Metabolic equivalents } \\
\text { per week }\end{array}$ & 230 & 963298 & 1.00 & $0.70(0.50-0.99)$ & $0.49(0.31-0.78)$ & $0.61(0.39-0.96)$ & 0.05 & \\
\hline Smoking & & & & & & & & 0.76 \\
\hline Never & 188 & 960486 & 1.00 & $0.76(0.50-1.15)$ & $0.65(0.39-1.08)$ & $0.54(0.32-0.93)$ & 0.03 & \\
\hline Ever & 278 & 1151748 & 1.00 & $0.93(0.66-1.32)$ & $0.71(0.46-1.09)$ & $0.77(0.49-1.19)$ & 0.14 & \\
\hline Red meat consumption & & & & & & & & 0.26 \\
\hline$\leqslant 1.0$ Servings per day & 294 & 1058710 & 1.00 & $1.00(0.71-1.41)$ & $0.65(0.42-1.01)$ & $0.70(0.45-1.08)$ & 0.02 & \\
\hline$>1.0$ Servings per day & 172 & 1053524 & 1.00 & $0.71(0.46-1.11)$ & $0.75(0.45-1.24)$ & $0.64(0.37-1.09)$ & 0.22 & \\
\hline Vegetable consumption & & & & & & & & 0.30 \\
\hline$\leqslant 2.5$ Servings per day & 195 & 1066486 & 1.00 & $0.78(0.89-1.75)$ & $0.51(0.75-1.79)$ & $0.58(0.50-1.25)$ & 0.02 & \\
\hline$>2.5$ Servings per day & 271 & 1045748 & 1.00 & $1.02(0.67-1.55)$ & $0.88(0.55-1.40)$ & $0.82(0.51-1.31)$ & 0.18 & \\
\hline Fruit consumption & & & & & & & & 0.33 \\
\hline$\leqslant 2.0$ Servings per day & 211 & 1058444 & 1.00 & $0.85(0.59-1.24)$ & $0.78(0.48-1.25)$ & $0.78(0.47-1.29)$ & 0.36 & \\
\hline$>2.0$ Servings per day & 255 & 1053790 & 1.00 & $0.91(0.61-1.34)$ & $0.65(0.41-1.03)$ & $0.62(0.39-0.98)$ & 0.01 & \\
\hline
\end{tabular}

insulin resistance and hyperinsulinaemia. Prospective observational studies have reported increased risk of pancreatic cancer among subjects with higher circulating insulin (StolzenbergSolomon et al, 2005) or C-peptide (Michaud et al, 2007) and among those with a history of type II diabetes (Everhart and Wright, 1995; Elena et al, 2013). Concurrently, studies have found that increasing nut intake was associated with decreased insulin levels (Estruch et al, 2006; Jenkins et al, 2006; Tapsell et al, 2009; Casas-Agustench et al, 2011b; O'Neil et al, 2012) and lower risk of developing metabolic syndrome (Salas-Salvado et al, 2008; Fernandez-Montero et al, 2013). Furthermore, some (Jiang et al, 2002; Villegas et al, 2008), though not all (Parker et al, 2003), prospective studies have shown that regular nut consumption was inversely associated with the risk of type II diabetes mellitus. In a previous analysis of this same cohort, higher nut consumption was associated with lower risk of type II diabetes (multivariate RR comparing $\geqslant 5$ times per week with almost never $=0.73 ; 95 \% \mathrm{CI}$, $0.60-0.89 ; P$ for trend $<0.001$ ) (Jiang et al, 2002). Similarly, a 
prospective, Chinese cohort of 64227 women found an inverse association between peanut consumption and risk of type II diabetes (multivariate RR comparing extreme quintiles $=0.80 ; 95 \%$ CI, 0.68-0.93; $P$ for trend $<0.0001$ ) (Villegas et al, 2008). Although the underlying mechanisms remain uncertain, nuts are rich in several nutrients associated with improved insulin sensitivity and decreased insulin demand and resistance, including unsaturated fatty acids, fibre, and magnesium (Anderson et al, 1987; Paolisso et al, 1989; Riserus et al, 2009). It is noteworthy that intakes of unsaturated fat, fibre, and magnesium were not associated with pancreatic cancer risk in this (Michaud et al, 2003) or other cohorts (Stolzenberg-Solomon et al, 2002; Kesavan et al, 2010; Molina-Montes et al, 2012).

Alternatively, other nutrients and bioactive compounds in nuts, such as vitamins (e.g., folate, niacin, vitamin E) and phytochemicals (e.g., carotenoids, flavonoids, and phytosterols), may confer antioxidant, anti-inflammatory, or anticancer properties (Gonzalez and Salas-Salvado, 2006). Indeed, observational studies and clinical trials have demonstrated beneficial effects of nuts on oxidative stress (Jenkins et al, 2006; Torabian et al, 2009) and inflammatory markers (Jiang et al, 2006). In addition, some studies reported that high serum $\alpha$-tocopherol, the biologically active form of vitamin E, was associated with a reduced risk of pancreatic cancer (Stolzenberg-Solomon et al, 2009). This evidence supports a role of nuts in pancreatic cancer prevention.

There may be a concern that frequent nut consumption may result in weight gain and therefore increase the risk of developing pancreatic cancer. However, in our cohort, women reporting greater nut intake tended to weigh less (Table 1). In fact, nut consumption has been shown to be associated with less weight gain (Bes-Rastrollo et al, 2007; Bes-Rastrollo et al, 2009; CasasAgustench et al, 2011a). A recent analysis of this same cohort found that higher nut consumption was associated with a slightly lower risk of weight gain and obesity (Bes-Rastrollo et al, 2009).

The strengths of this study include its prospective design, large sample size, and $>30$ years of follow-up. Our validation data indicate that nut intake was measured reasonably accurately (Salvini et al, 1989); in addition, we updated nut consumption repeatedly during follow-up, thereby accounting for true changes in diet and reducing measurement error. Moreover, as dietary data were collected prospectively, any misclassification of exposure should be random, thereby biasing the association towards the null. Although participants with subclinical pancreatic cancer may have decreased their nut consumption, the inverse association persisted when we added a 4-year lag period between nut intake and each follow-up period.

Our study also has limitations. Although we cannot exclude residual confounding by other potential risk factors for pancreatic cancer, our study provided detailed information on the lifestyle and diet of the participants. In our analysis, we adjusted for BMI, physical activity, smoking, diabetes history, and other relevant dietary factors, and the results were virtually unchanged. In addition, the inverse association persisted across all subgroups (e.g., subgroups defined by BMI, physical activity, smoking, red meat, fruits, and vegetables), further suggesting an independent inverse association. Because our study population is relatively homogeneous in education and occupation, confounding by socioeconomic status was minimised. Although we cannot rule out the possibility of confounding by unknown risk factors, it is unlikely that it can fully explain the observed modest association (Flanders and Khoury, 1990).

In conclusion, frequent nut consumption was associated with a reduced risk of pancreatic cancer in this large prospective cohort study of women. Although additional confirmatory studies are warranted, our findings offer potential insights into both the prevention and biology of this highly fatal and poorly understood malignancy.

\section{ACKNOWLEDGEMENTS}

This study is supported by the Grants P01 CA87969, R01 CA124908, and 1U54CA155626-01 from the National Institutes of Health, and by the grant from the International Tree Nut Council Nutrition Research \& Education Foundation. The work is also supported in part by a micro-grant from the Biomedical Research Institute at the Brigham and Women's Hospital. In addition, we thank the participants and staff of the Nurses' Health Study for their valuable contributions, as well as the following state cancer registries for their help: AL, AZ, AR, CA, CO, CT, DE, FL, GA, ID, IL, IN, IA, KY, LA, ME, MD, MA, MI, NE, NH, NJ, NY, NC, ND, OH, OK, OR, PA, RI, SC, TN, TX, VA, WA, and WY.

The sponsors did not participate in the design and conduct of the study; collection, management, analysis, and interpretation of the data; and preparation, review, or approval of the manuscript.

\section{CONFLICT OF INTEREST}

Dr Bao reported receiving a research grant from the International Tree Nut Council Nutrition Research \& Education Foundation.

\section{AUTHOR CONTRIBUTIONS}

Dr Bao had full access to all of the data in the study and takes responsibility for the integrity of the data and the accuracy of the data analysis. Study concept and design: Bao and Fuchs; acquisition of data: $\mathrm{Hu}$, Giovannucci, Stampfer, Willett, and Fuchs; analysis and interpretation of data: $\mathrm{Bao}, \mathrm{Hu}$, Giovannucci, Wolpin, Stampfer, Willett, and Fuchs; drafting of the manuscript: Bao and Fuchs; critical revision of the manuscript for important intellectual content: Bao, Hu, Giovannucci, Wolpin, Stampfer, Willett, and Fuchs; statistical analysis: Bao and Fuchs; obtained funding: Bao and Fuchs; administrative, technical, or material support: Hu, Giovannucci, Stampfer, Willett, and Fuchs; study supervision: Fuchs.

\section{REFERENCES}

Anderson JW, Gustafson NJ, Bryant CA, Tietyen-Clark J (1987) Dietary fiber and diabetes: a comprehensive review and practical application. J Am Diet Assoc 87: 1189-1197.

Bes-Rastrollo M, Sabate J, Gomez-Gracia E, Alonso A, Martinez JA, Martinez-Gonzalez MA (2007) Nut consumption and weight gain in a Mediterranean cohort: the SUN study. Obesity (Silver Spring) 15: 107-116. Bes-Rastrollo M, Wedick NM, Martinez-Gonzalez MA, Li TY, Sampson L, Hu FB (2009) Prospective study of nut consumption, long-term weight change, and obesity risk in women. Am J Clin Nutr 89: 1913-1919.

Bosetti C, Turati F, Pont AD, Ferraroni M, Polesel J, Negri E, Serraino D, Talamini R, Vecchia CL, Zeegers MP (2013) The role of Mediterranean diet on the risk of pancreatic cancer. Br J Cancer 109: 1360-1366.

Brufau G, Boatella J, Rafecas M (2006) Nuts: source of energy and macronutrients. Br J Nutr 96(Suppl 2): S24-S28.

Bueno de Mesquita HB, Maisonneuve P, Runia S, Moerman CJ (1991) Intake of foods and nutrients and cancer of the exocrine pancreas: a population-based case-control study in the Netherlands. Int J Cancer 48 : 540-549.

Casas-Agustench P, Bullo M, Ros E, Basora J, Salas-Salvado J (2011a) Cross-sectional association of nut intake with adiposity in a Mediterranean population. Nutr Metab Cardiovasc Dis 21: 518-525.

Casas-Agustench P, Lopez-Uriarte P, Bullo M, Ros E, Cabre-Vila JJ, Salas-Salvado J (2011b) Effects of one serving of mixed nuts on serum lipids, insulin resistance and inflammatory markers in patients with the metabolic syndrome. Nutr Metab Cardiovasc Dis 21: 126-135. 
Elena JW, Steplowski E, Yu K, Hartge P, Tobias GS, Brotzman MJ, Chanock SJ, Stolzenberg-Solomon RZ, Arslan AA,

Bueno-de-Mesquita HB, Helzlsouer K, Jacobs EJ, LaCroix A, Petersen G, Zheng W, Albanes D, Allen NE, Amundadottir L, Bao Y, Boeing H, Boutron-Ruault MC, Buring JE, Gaziano JM, Giovannucci EL, Duell EJ, Hallmans G, Howard BV, Hunter DJ, Hutchinson A, Jacobs KB, Kooperberg C, Kraft P, Mendelsohn JB, Michaud DS, Palli D, Phillips LS, Overvad K, Patel AV, Sansbury L, Shu XO, Simon MS, Slimani N, Trichopoulos D, Visvanathan K, Virtamo J, Wolpin BM, ZeleniuchJacquotte A, Fuchs CS, Hoover RN, Gross M (2013) Diabetes and risk of pancreatic cancer: a pooled analysis from the pancreatic cancer cohort consortium. Cancer Causes Control 24: 13-25.

Estruch R, Martinez-Gonzalez MA, Corella D, Salas-Salvado J, Ruiz-Gutierrez V, Covas MI, Fiol M, Gomez-Gracia E, Lopez-Sabater MC, Vinyoles E, Aros F, Conde M, Lahoz C, Lapetra J, Saez G, Ros E (2006) Effects of a Mediterranean-style diet on cardiovascular risk factors: a randomized trial. Ann Intern Med 145: 1-11.

Everhart J, Wright D (1995) Diabetes mellitus as a risk factor for pancreatic cancer. A meta-analysis. JAMA 273: 1605-1609.

Fernandez-Montero A, Bes-Rastrollo M, Beunza JJ, Barrio-Lopez MT, de la Fuente-Arrillaga C, Moreno-Galarraga L, Martinez-Gonzalez MA (2013) Nut consumption and incidence of metabolic syndrome after 6-year follow-up: the SUN (Seguimiento Universidad de Navarra, University of Navarra Follow-up) cohort. Public Health Nutr 16: 2064-2072.

Flanders WD, Khoury MJ (1990) Indirect assessment of confounding: graphic description and limits on effect of adjusting for covariates. Epidemiology 1: 239-246.

Giovannucci E, Michaud D (2007) The role of obesity and related metabolic disturbances in cancers of the colon, prostate, and pancreas. Gastroenterology 132: 2208-2225.

Gonzalez CA, Salas-Salvado J (2006) The potential of nuts in the prevention of cancer. Br J Nutr 96(Suppl 2): S87-S94.

Hu FB, Stampfer MJ, Manson JE, Rimm E, Colditz GA, Rosner BA, Hennekens CH, Willett WC (1997) Dietary fat intake and the risk of coronary heart disease in women. $N$ Engl J Med 337: 1491-1499.

Jemal A, Siegel R, Xu J, Ward E (2010) Cancer statistics, 2010. CA Cancer J Clin 60: 277-300.

Jenkins DJ, Kendall CW, Josse AR, Salvatore S, Brighenti F, Augustin LS, Ellis PR, Vidgen E, Rao AV (2006) Almonds decrease postprandial glycemia, insulinemia, and oxidative damage in healthy individuals. J Nutr 136: 2987-2992.

Jiang R, Jacobs Jr. DR, Mayer-Davis E, Szklo M, Herrington D, Jenny NS, Kronmal R, Barr RG (2006) Nut and seed consumption and inflammatory markers in the multi-ethnic study of atherosclerosis. Am J Epidemiol 163 222-231.

Jiang R, Manson JE, Stampfer MJ, Liu S, Willett WC, Hu FB (2002) Nut and peanut butter consumption and risk of type 2 diabetes in women. JAMA 288: 2554-2560.

Kesavan Y, Giovannucci E, Fuchs CS, Michaud DS (2010) A prospective study of magnesium and iron intake and pancreatic cancer in men. Am J Epidemiol 171: 233-241.

Larsson SC, Orsini N, Wolk A (2007) Body mass index and pancreatic cancer risk: a meta-analysis of prospective studies. Int J Cancer 120: 1993-1998.

Michaud DS, Giovannucci E, Willett WC, Colditz GA, Fuchs CS (2003) Dietary meat, dairy products, fat, and cholesterol and pancreatic cancer risk in a prospective study. Am J Epidemiol 157: 1115-1125.

Michaud DS, Wolpin B, Giovannucci E, Liu S, Cochrane B, Manson JE, Pollak MN, Ma J, Fuchs CS (2007) Prediagnostic plasma C-peptide and pancreatic cancer risk in men and women. Cancer Epidemiol Biomarkers Prev 16: 2101-2109.

Molina-Montes E, Wark PA, Sanchez MJ, Norat T, Jakszyn P, Lujan-Barroso L, Michaud DS, Crowe F, Allen N, Khaw KT, Wareham N, Trichopoulou A, Adarakis G, Katarachia H, Skeie G, Henningsen M, Broderstad AR, Berrino F, Tumino R, Palli D, Mattiello A, Vineis P, Amiano P, Barricarte A, Huerta JM, Duell EJ, Quiros JR, Ye W, Sund M, Lindkvist B, Johansen D, Overvad K, Tjonneland A, Roswall N, Li K, Grote VA, Steffen A, Boeing H, Racine A, Boutron-Ruault MC, Carbonnel F, Peeters PH, Siersema PD, Fedirko V, Jenab M, Riboli E,
Bueno-de-Mesquita B (2012) Dietary intake of iron, heme-iron and magnesium and pancreatic cancer risk in the European prospective investigation into cancer and nutrition cohort. Int J Cancer 131: E1134-E1147.

O'Neil CE, Keast DR, Nicklas TA, Fulgoni 3rd VL (2011) Nut consumption is associated with decreased health risk factors for cardiovascular disease and metabolic syndrome in U.S. adults: NHANES 1999-2004. J Am Coll Nutr 30: $502-510$.

O’Neil CE, Keast DR, Nicklas TA, Fulgoni 3rd VL (2012) Out-of-hand nut consumption is associated with improved nutrient intake and health risk markers in US children and adults: National Health and Nutrition Examination Survey 1999-2004. Nutr Res 32: 185-194.

Paolisso G, Sgambato S, Pizza G, Passariello N, Varricchio M, D’Onofrio F (1989) Improved insulin response and action by chronic magnesium administration in aged NIDDM subjects. Diabetes Care 12: 265-269.

Parker ED, Harnack LJ, Folsom AR (2003) Nut consumption and risk of type 2 diabetes. JAMA 290: 38-39author reply 39-40.

Rich-Edwards JW, Corsano KA, Stampfer MJ (1994) Test of the National Death Index and Equifax Nationwide Death Search. Am J Epidemiol 140: 1016-1019.

Riserus U, Willett WC, Hu FB (2009) Dietary fats and prevention of type 2 diabetes. Prog Lipid Res 48: 44-51.

Salas-Salvado J, Fernandez-Ballart J, Ros E, Martinez-Gonzalez MA, Fito M, Estruch R, Corella D, Fiol M, Gomez-Gracia E, Aros F, Flores G, Lapetra J, Lamuela-Raventos R, Ruiz-Gutierrez V, Bullo M, Basora J, Covas MI (2008) Effect of a Mediterranean diet supplemented with nuts on metabolic syndrome status: one-year results of the PREDIMED randomized trial. Arch Intern Med 168: 2449-2458.

Salvini S, Hunter DJ, Sampson L, Stampfer MJ, Colditz GA, Rosner B, Willett WC (1989) Food-based validation of a dietary questionnaire: the effects of week-to-week variation in food consumption. Int J Epidemiol 18: 858-867.

Stolzenberg-Solomon RZ, Graubard BI, Chari S, Limburg P, Taylor PR, Virtamo J, Albanes D (2005) Insulin, glucose, insulin resistance, and pancreatic cancer in male smokers. JAMA 294: 2872-2878.

Stolzenberg-Solomon RZ, Pietinen P, Taylor PR, Virtamo J, Albanes D (2002) Prospective study of diet and pancreatic cancer in male smokers. Am J Epidemiol 155: 783-792.

Stolzenberg-Solomon RZ, Sheffler-Collins S, Weinstein S, Garabrant DH, Mannisto S, Taylor P, Virtamo J, Albanes D (2009) Vitamin E intake, alpha-tocopherol status, and pancreatic cancer in a cohort of male smokers. Am J Clin Nutr 89: 584-591.

Tapsell LC, Batterham MJ, Teuss G, Tan SY, Dalton S, Quick CJ, Gillen LJ, Charlton KE (2009) Long-term effects of increased dietary polyunsaturated fat from walnuts on metabolic parameters in type II diabetes. Eur J Clin Nutr 63: 1008-1015.

Torabian S, Haddad E, Rajaram S, Banta J, Sabate J (2009) Acute effect of nut consumption on plasma total polyphenols, antioxidant capacity and lipid peroxidation. J Hum Nutr Diet 22: 64-71.

Trichopoulou A, Costacou T, Bamia C, Trichopoulos D (2003) Adherence to a Mediterranean diet and survival in a Greek population. N Engl J Med 348: 2599-2608.

Villegas R, Gao YT, Yang G, Li HL, Elasy TA, Zheng W, Shu XO (2008) Legume and soy food intake and the incidence of type 2 diabetes in the Shanghai Women's Health Study. Am J Clin Nutr 87: 162-167.

WCRF/AICR (2009) World Cancer Research Fund / American Institute for Cancer Research Food, Nutrition, Physical Activity, and the Prevention of Cancer: A Global Perspective. AICR: Washington DC.

Willett WC, Sampson L, Stampfer MJ, Rosner B, Bain C, Witschi J, Hennekens CH, Speizer FE (1985) Reproducibility and validity of a semiquantitative food frequency questionnaire. Am J Epidemiol 122: 51-65.

This work is published under the standard license to publish agreement. After 12 months the work will become freely available and the license terms will switch to a Creative Commons AttributionNonCommercial-Share Alike 3.0 Unported License. 